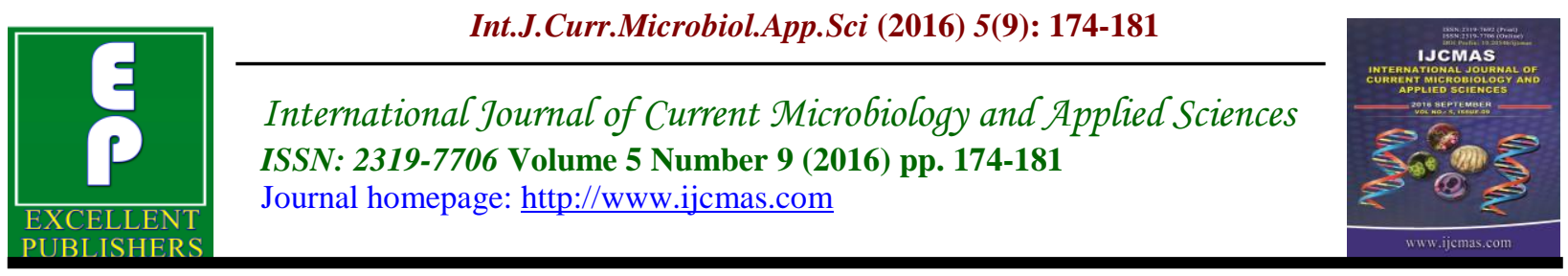

Original Research Article

http://dx.doi.org/10.20546/ijcmas.2016.509.019

\title{
Bacterial Colonization and Biofilm Formation among Diabetic Patients: A Therapeutic Challenge
}

\author{
Pallavi Sayal $^{1 *}$, Pushpa Devi ${ }^{2}$ and Kanwardeep Singh ${ }^{2}$ \\ ${ }^{1}$ Department of Microbiology, BPS, GMC (W), Khanpurkalan, Sonepat, Haryana, India \\ ${ }^{2}$ Department of Microbiology, Govt Medical College, Amritsar, India \\ *Corresponding author
}

\begin{abstract}
A B S T R A C T
Recent advancements in technology has brought to use, plethora of implants or devices made of inert metals, plastics and other synthetic products. Unfortunately, adhesion and attraction of the bacteria to these surfaces made them extremely prone to bacterial biofilm formation. Effects of diabetes, promotes bacterial colonization and allows bacteriuria to easily extend resulting in urosepsis. Present study is

Keywords

Bacterial

Colonization and

Biofilm Formation,

Diabetic

Patients

\section{Article Info}

Accepted:

13 August 2016

Available Online:

10 September 2016 designed to provide insight into bacterial colonization and biofilm formation among diabetic patients with indwelling urinary catheters. This prospective study was done on 189 randomly selected urinary catheterized diabetic patients with significant bacteriuria (symptomatic and asymptomatic). Semi-quantitative bacterial culture was performed and isolates were identified by standard biochemical tests. Biofilm formation was Tissue Culture Plate Method. One hundred and two (53.96\%) patients had asymptomatic bacteriuria (ASB) and 87/189(46.03\%) had urinary tract infection (UTI). Females (57.84\%) were frequently seen with ASB than men $(42.15 \%)$ and ASB was more common in the age group between 46 and 60 years $(27.2 \%)$.Urinary tract infections on the other hand were more common in males $(65.51 \%)$ than in females $(34.48 \%)$.Escherichia coli was most common isolate 59/189(31.12\%) followed by Klebsiella spp 50/189(26.45\%). Biofilm formation was observed among 140/189 (74.07\%) isolates, out of which 55/189(29.10\%) were high, 85/189(44.97\%) were moderate and 49/189(25.92\%) were non biofilm producers. Indwelling bladder catheters are commonly deployed prosthetic medical devices, unfortunately they also provide access for bacteria from contaminated external environment into a vulnerable body cavity. Biofilm-like pods explains how bladder infections can persist in the face of robust host defense. Therefore, very dynamic research activity in the biofilm field is required.
\end{abstract}

\section{Introduction}

Commonly encountered as a layer on slime clogging drainpipes, biofilms appear in our everyday life in more than one form (Kumar et al., 2006). Health care providers have traditionally envisioned bacteria in their free-floating or planktonic state, and planktonic organisms have been the focus of traditional microbiologic methods of sampling and culture. However, the predominant form of life for the majority of 
microorganisms in any hydrated biologic system, such as the human body, is a cooperative community termed a "biofilm" (Traunter et al., 2004).

\section{Mechanism of Bacterial Biofilm Formation}

Biofilm formation usually commences with the colonization of a surface by bacteria. The adhesion and attraction of the bacteria to the surface may be brought about by different mechanisms including surface charge, gravity, Brownian motion and chemo attraction, provided the surface has nutrients. After attraction, attachment of the bacteria to the surface occurs by a two-step process comprised of reversible binding. The reversible binding is usually brought about by weak Vander Waal forces to hold the bacterium close to the surface before a stronger attachment can form by a combination of both, physical and chemical forces. Production of exogenous polysaccharide containing material exuded by bacteria is one of such chemical substances implicated, also called as the glycocalyx. Bacteria divide and grow freely within this glycocalyx to form micro colonies eventually forming a biofilm.

It is estimated that biofilms contribute to more than $80 \%$ of human infections. Biofilm-linked infections are particularly problematic as bacteria in biofilms can withstand host immune defenses, antibiotics, biocides, and hydrodynamic shear forces far better than the corresponding planktonic bacteria. These characteristics made such infections recalcitrant to treatment, and it is common and frustrating experience that after treatment, surviving biofilm-associated bacteria will carry on the infection (Hancock et al., 2010).
Recent advancements in technology has brought to use, plethora of implants or devices made of inert metals, plastics and other synthetic products such as: Orthopedic implants, Ocular lenses, heart valves, vascular grafts, intra uterine devices, temporary indwelling catheters and intravenous catheters. Between $15 \%$ and $25 \%$ of patients in hospitals will have a urinary catheter in place sometime during their stay. Unfortunately, catheters are extremely prone to bacterial biofilm formation.

Diabetes is characterized by variable degrees of insulin resistance, impaired insulin secretion, and increased glucose production. Patients with DM are at increased risk of infections, with the urinary tract being the most frequent infection site (Nitzan et al., 2015).

Main mechanism being defect in the local urinary cytokines (IL8 and IL6) and also hyperglycemia facilitating increased colonization by uropathogens in the urinary tract (Priyadarshini et al., 2014). Spectrum of Urinary tract infection (UTI) in these patients' ranges from asymptomatic bacteriuria (ASB) to lower UTI, pyelonephritis, and severe urosepsis. Serious complications of UTI, such as emphysematous cystitis and pyelonephritis, renal abscesses and renal papillary necrosis, are all encountered more frequently than in the general population.

Because this biofilm lifestyle is associated with human infectious diseases and account for $80 \%$ of bacterial chronic inflammatory and infectious diseases, several lines of research are currently focusing on the possibility of hacking into biofilm initiation, structuration or communication, and promoting dispersion, even though we are far from understanding the complex genetic basis for biofilm formation in vivoThus, 
present study is designed to provideinsight into bacterial colonization and biofilm formation among diabetic patients with indwelling urinary catheters.

\section{Materials and Methods}

This prospective study was undertaken in the Department of Microbiology in a tertiary care hospital. A total of 189 randomly selected urinary catheterized diabetic patients with significant bacteriuria (symptomatic and asymptomatic), admitted in various wards of hospital were included in present study. Urine samples were collected in sterile containers with proper aseptic precautions. Samples were cultured on Mac Conkey agar and blood agar and incubated overnight aerobically at $37^{\circ} \mathrm{C}$. A specimen was considered positive, if a single / two potential pathogens were cultured at a concentration of $\geq 10^{5}$ Colony forming unit $(\mathrm{CFU}) / \mathrm{ml}$ from catheterized urine specimens (Collee et al., 2006). The organisms identified by conventional microbiological methods were subjected to biofilm detection by the following method-

\section{Tissue Culture Plate Method (Tcp) (Christensen et al., 1985)}

Organisms isolated from fresh agar plates were inoculated in Brain heart infusion broth (BHI) with 2\% sucrose. Broth was incubated at $37^{\circ} \mathrm{C}$ for 18 hours. The broth culture was then diluted 1:100 with fresh medium. Individual wells of sterile 96 well flat bottom polystyrene tissue culture plates were filled with $200 \mathrm{ul}$ of the diluted cultures. The wells were washed with phosphate buffer saline (ph 7.2). Biofilm formed by bacteria adherent to the wells was fixed by $2 \%$ sodium acetate and stained by crystal violet $(0.1 \%)$. Excess stain was removed by using deionized water and plates will be kept for drying. Optical density (OD) of stained adherent bacteria was determined with an ELISA reader at wavelength of $570 \mathrm{~nm}\left(\mathrm{OD}_{570 \mathrm{~nm}}\right)$. These OD values were considered as an index of bacteria adhering to surface and forming biofilm.

\section{Results and Discussion}

Demographic characteristics of study showed that majority of patients were males $109 / 189(57.67 \%$ and 80/189(42.32\%) were females. One hundred and two (53.96\%) patients had asymptomatic bacteriuria (ASB) and 87/189(46.03\%) had urinary tract infection (UTI). Females (57.84\%) were frequently seen with ASB than men $(42.15 \%)$ and ASB was more common in the age group between 46 and 60 years $(27.2 \%)$ (Table 1).

Urinary tract infections on the other hand were more common in males $(65.51 \%)$ than in females $(34.48 \%$ ) (Table 2). ASB and UTIs were least prevalent in the most sexually active age group of 20 to 40 year.

Escherichia coli was most common isolate 59/189(31.12\%) followed by Klebsiella spp $50 / 189(26.45 \%)$. Distribution of pathogens according to duration of catheterization of the diabetic patients is summarized in Table 3.

In present study biofilm formation was observed among 140/189 (74.07\%) isolates,out of which $55 / 189(29.10 \%)$ were high, $85 / 189(44.97 \%)$ were moderate and 49/189(25.92\%) were non biofilm producers. Results of phenotypic detection by TCP for biofilm formation as shown in Table 4.

Indwelling bladder catheters are commonly deployed prosthetic medical devices, unfortunately they also provide access for 
bacteria from contaminated external environment into a vulnerable body cavity. Implanted prosthetic devices constitute particularly attractive surfaces for bacterial colonization, as they have none of the protective mechanisms of healthy tissue surfaces (Morris et al., 1999). Occurrence of bacteriuria is inevitable while the urinary catheter is in place. In prospective studies by Garibaldi et al., (1982) and Warren et al., (1982) the daily risk of bacteriuria with catheterization ranged from $3 \%$ to $10 \%$ and approached $100 \%$ after 28 days, which is considered to be the delineation between short- and long-term catheterization.

In present study, ASB was observed among $102 / 189(53.96 \%)$ and UTI was seen among 87/189(46.03\%) diabetic patients. Higher prevalence of ASB was observed in our study as compared to $36.15 \%$ observed by Hajeri (2008), 19\% by Baqai et al., (1982) and $21 \%$ by Alebiosu et al., (2003). Relationship between catheter-associated ASB and catheter associated urinary tract infection (CAUTI) is unclear, but the presence of ASB is necessary for the development of CAUTI. The development of urinary symptoms must require some facilitating events, and as the duration of catheterization is increased, the possibility of events occurring is increased also. In addition, ASB represents a large reservoir of antimicrobial-resistant urinary pathogens that may be transmitted to other patients and frequently triggers inappropriate antimicrobial use. Therefore, the greatest impact of an intervention may be to reduce the frequent occurrence of $\mathrm{ASB}$, and the reduction of inappropriate urinary catheter durations is important for that (Hooton et al., 2010).

Geerling and colleagues (Geerling et al., 2000) reported a prevalence of UTIs of $26.0 \%$ in diabetic patients where as high prevalence was observed $(43.06 \%)$ in our study. Geerlings and Hoepelman (1999) noted that in patients with diabetes, impaired granulocyte function, increased adherence of uropathogens to bladder epithelial cells, and the effects of glucosuria on the growth of uropathogens in diabetic patients contribute to a higher UTI prevalence. Platt et al., (1986) also documented the presence of diabetes as a risk factor and proposed two possibilities for why diabetic patients are at increased risk of acquiring infection: an increased prevalence of perineal colonization by potential pathogens and an increased ability of the urine of some patients with diabetes to support microbial growth. These effects of diabetes promote the colonization of uropathogens on the catheter surface when urinary catheters are indwelled and affect the synthesis of biofilms. In addition, the immunocompromised state, which is a characteristic of these patients, allows bacteriuria to easily extend into the upper urinary tract. Diabetic patients, especially those admitted to the hospital with indwelling catheters, are more susceptible to the development of urosepsis; thus, these patients require strict blood glucose monitoring to prevent catheter associated UTI (CA-UTI) occurrence and progression (Lee et al., 2013).

In our study Escherichia coli was most common isolate 59/189(31.12\%) followed by Klebsiella spp50/189(26.45\%). E.coli is responsible for more than $80 \%$ of the UTIs and it causes both symptomatic UTIs and ASB The ability of Uropathogenic E.coli (UPEC) to cause UTI is associated with the expression of variety of virulence factors, which include adhesions(e.g Type 1 and $\mathrm{P}$ fimbriae) and toxins (e.ghaemolysins) (Hedlund et al., 2001). In our study, Klebsiella spp, Pseudomonasaeruginosa and Proteus mirabilis were among common 
isolated organisms as duration of catheterization increases(cut off 7 days). Johansen et al., (2004), Tambyah et al., (2004) have indicated that the cut-off point for the duration of catheterization increasing the infection rate is 3 days where as Langley JL et al., (2005) and Lohr et al., (1994) have suggested that the cut-off point is 7 days. Langley and co-workers also suggested that infection rate was 95 per cent, especially in patients catheterized more than 28 days. This rate was 10 times higher than that of the seventh day of catheterization. In the present study, 7 days was taken as cut off for duration of catheterization. Also, as per our hospital policy catheters are usually replaced 10-14 days after insertion.

In our study biofilm formation was observed among 140/189 (74.07\%) isolates, out of which 55/189(29.10\%) were high,85/189(44.97\%) were moderate and 49/189(25.92\%) were non biofilm producers (Table 4). Our study is in concordance with Mangaiyarkarasi et al., (2014) who observed $66 \%$ biofilm among bacterial isolates from diabetic patients.

Table.1 Classification of bacterial adherence by TCP method

\begin{tabular}{|l|l|l|}
\hline Mean OD & Adherence & Biofilm Formation \\
\hline$<0.120$ & Non & Non/weak \\
\hline $0.120-0.240$ & Moderate & Moderate \\
\hline$>0.240$ & Strong & High \\
\hline
\end{tabular}

Table.2 Age and Gender distribution of patients with Asymptomatic Bacteriuria

\begin{tabular}{|l|l|l|l|}
\hline Age Distribution & Males & Females & Total \\
\hline $15-30$ & 09 & 02 & 11 \\
\hline $31-45$ & 03 & 14 & 17 \\
\hline $46-60$ & 16 & 25 & 41 \\
\hline$>60$ & 15 & 18 & 33 \\
\hline
\end{tabular}

Table.3 Age and Gender distribution of patients with Urinary tract infection

\begin{tabular}{|l|l|l|l|}
\hline Age Distribution & Males & Females & Total \\
\hline $15-30$ & 04 & 06 & 10 \\
\hline $31-45$ & 18 & 09 & 27 \\
\hline $46-60$ & 20 & 07 & 27 \\
\hline$>60$ & 15 & 08 & 23 \\
\hline
\end{tabular}

Table.4 Bacteriological profile of isolates according to duration of catheterization

\begin{tabular}{|l|l|l|l|}
\hline \multirow{2}{*}{ Bacterial Isolates } & Duration of Catheterization & Total \\
\cline { 2 - 4 } & $<7$ days & $>7$ days & \\
\hline Escherichia coli & 42 & 17 & 59 \\
\hline Klebsiella spp. & 21 & 29 & 50 \\
\hline Pseudomonas aeruginosa & 08 & 20 & 28 \\
\hline Proteus mirabilis & 05 & 17 & 22 \\
\hline Proteus vulgaris & - & 02 & 02 \\
\hline Citrobacter spp. & 04 & 02 & 06 \\
\hline Enterococcus spp. & 05 & 03 & 08 \\
\hline Coagulase negative Staphylococcus spp. & 09 & 05 & 14 \\
\hline
\end{tabular}


Table.5 Biofilm detection by TCP method

\begin{tabular}{|l|l|l|l|}
\hline \multirow{2}{*}{ Bacterial isolates } & \multicolumn{3}{l|}{ Biofilm detection by TCP } \\
\cline { 2 - 4 } & High & Moderate & Non/weak \\
\hline Escherichia coli & 09 & 36 & 14 \\
\hline Klebsiella spp. & 12 & 25 & 13 \\
\hline Pseudomonas aeruginosa & 15 & 08 & 05 \\
\hline Proteus mirabilis & 12 & 07 & 03 \\
\hline Proteus vulgaris & - & 01 & 01 \\
\hline Citrobacter spp. & 01 & 01 & 04 \\
\hline Enterococcus spp. & 03 & 03 & 02 \\
\hline Coagulase Negative Staphylococcus spp. & 03 & 04 & 07 \\
\hline
\end{tabular}

Pascual and Sheretz documented with regard to the pathogenesis of catheter related infection and its relation with duration of catheters that over time, in a short term one, catheters are colonized by skin microorganisms or faecal contaminants (70$90 \%$ ), followed by bacteria from the hub/lumen (10-50\%), the blood stream (3$10 \%)$ and infusate $(3 \%)$. In the case of long term catheters, the most frequent source of colonization is the hub followed by the skin.

Also, Nickel and associates indicated that in short term catheterization (less than 7 days), contamination of the drainage spout or accidental disconnection of the drainage tube results in bacteriuria within a short time (32-48 hours). If strict sterile closed drainage system was maintained, the external route assumed more importance in development of bacteriuria; however this pathway was considerably slower (3-7days). It appeared that catheter-associated bacteriuria results from ascending bacterial colonization within biofilm on the inside and/or outside surfaces of the catheter and drainage systems. For either short or long term catheters, the infection rate was about $5 \%$ per day (Nicolle et al., 2005).

Bacteria invading urinary tract met with potent innate defenses, including neutrophil influx and epithelial exfoliation. Bacterial subversion of innate responses involves invasion into bladder superficial cell and bacteria matured into biofilms, creating podlike bulges on the bladder surface. Pods contained bacteria encased in a polysaccharide-rich matrix surrounded by a protective shell of uroplakin.

Thus, biofilm-like pods explains how bladder infections can persist in the face of robust host defense. They are associated with a large number of persistent and chronic infections. Biofilm-dwelling bacteria are particularly resistant to antibiotics, which makes it hard if not impossible to eradicate biofilm-associated infections (Anderson et al., 2003).

Thus we conclude Biofilms in vivo are very difficult to diagnose essentially due to the lack of sampling methods and markers, but bacterial cell clusters in discrete areas in the host tissue associated with host inflammatory cells can signal such biofilm infections. Global efforts are required to understand how bacteria form biofilms in patients, especially when considering that invivo bacterial situations can widely differ with in vitro behavior. Therefore, very dynamic research activity in the biofilm field is required, especially because this bacterial lifestyle are associated with human infectious diseases particularly resistant to antibiotics. 


\section{References}

Alebiosu, C.O., Osinupebi, O.A., Olajubu, F.A. 2003. Significant asymptomatic bacteriuria among Nigerian type 2 diabetes. J. Natl. Med. Assoc., 95(5): 344-8. [PMC:2594521]

Anderson, G.G., Palermo, J.J., Schilling, J.D., Roth, R., Heuser, J., Hultgren, S.J. 2003. Intracellular bacterial biofilm-like pods in urinary tract infections. Sci., 4: 301(5629):105-7. [PMID:12843396]

Baqai, R., Aziz, M., Rasool, G. 2008. Urinary tract infections in diabetic patients and biofilm formation of uropathogens. Infect. Dis. J. Pak., 17(1): 21-4.

Christensen, G.D., Simpson, W.A., Younger, J.A., Baddour, L.M., Barrett, F.F., Melton, D.M. et al., 1985. Adherence of Coagulase negative Staphylococci to plastic tissue cultures: a quantitative model for the adherence of Staphylococci to medical devices. $J$. Clin. Microbiol., 22: 996-1006. [PMID: 3905855 PMCID:PMC271866]

Collee, J.G., Duguid, J.P., Fraser, A.G., Marmion, B.P., Simmons, A. 2006. Laboratory strategy in the diagnosis of infective syndrome. In Collee JG, Fraser AG, Marmion BP, Simmons A, editors. Mackie \& McCartney Practical Medical Microbiology. 14thed. New Delhi: Elsevier, a division of Reed Elsevier India Pvt. Ltd. P. 53-94.

Garibaldi, R.A., Mooney, B.R., Epstein, B.J., Britt, M.R. 1982. An evaluation of daily bacteriologic monitoring to identify preventable episodes of catheterassociated urinary tract infection. Infect. Control, 3: 466-70. [PMID:6924646]

Geerling, S.E., Stolk, R.P., Camps, M.J., Netten, P.M., Hoekstra, J.B., Bouter, K.P. et al. 2000 Asymptomatic bacteriuria may be considered a complication in women with diabetes:Diabetes mellitus women asymptomatic bacteriuria. Utrecht Study group. Diabetes Care, 23(6): 744-9. [PMID:10840989]

Geerlings, S.E., Hoepelman, A.I. 1999. Immune dysfunction in patients with diabetes mellitus (DM). FEMS Immunol. Med. Microbiol., 26(3-4): 259-65. [PMID:10575137]

Hajeri, A. 2008. When to treat asymptomatic bacteriuria. Brahain Med. Bull., 30(2): $1-4$.

Hancock, V., Dahl, M., Klemm, P. 2010. Abolition of bioflm formation urinart tract Escherichia coli and Klebsiella Isolates by metal interference through competition for fur. Appl. Environ. Microbiol., $\quad$ 76(12): 3836-41. [Doi:10.1128/AEM.00241-10]

Hedlund, M., Duan, R.D., Nilsson, A., Svensson, M., Karpman, D., Svanborg, C. 2001. The fimbriae, the transmembrane signalling, and the cell activation. J. infect. Dis., 183: 47-50.

Hooton, T.M., Bradley, S.F., Cardenas, D.D., Colgan, R., Geerlings, S.E., Rice, J.C. et al. 2009. Diagnosis, prevention, and treatment of catheter-associated urinary tract infection in adults: 2009 International Clinical Practice Guidelines from the Infectious Diseases Society of America. Clin. Infect. Dis., 50(5): 625-63. [PMID:20175247]

Johansen, T.E.B. 2004. Nosocomialy acquired urinary tract infections in urology departments, why an international prevalence study is needed in urology. Int. J. Antimicrob. Agents, 23S: S30-4.[ PMID: 15037326 DOI:10.1016/j.ijantimicag.2003.09.003]

Kumar, A., Prasad, R. 2006. Biofilms. J. K. Sci., 8(1): 14-7.

Langley, J.M. 2005. Defining urinary tract infection in the critically ill child. Pediatr. Crit. Care Med., 6: 25-9.[ PMID:15857553 DOI:10.1097/01.PCC.0000161934.7927 $0.66]$

Lee, J.H., Kim, S.W., Byung, Y., Wan, D., Cho, W.H. 2013. Factors That Affect 
Nosocomial Catheter-Associated Urinary Tract Infection in Intensive Care Units: 2-Year Experience at a Single Center. Korean J. Urol., 54: 5965. [doi:10.4111/kju.2013.54.1.59]

Lohr, J.A., Downs, S.M., Dudley, S., Donowitz, L.G. 1994. Hospital-acquired urinary tract infections in the pediatric patient: a prospective study. Pediatr. Infect. Dis. J., 13: 8-12. [PMID:8170742].

Morris, N.S., Stickler, D.J., Mclean, R.J. 1999. The development of bacterial biofilm on indwelling catheters. World J. Urol., 17(6): 343-50. [PMID:10654346]

Nickel, J.C., Ruseska, I., Wright, J.B., Costerton, J.W. 1985. Tobramycin resistance of Pseudomonas aeruginosa cells growing as a biofilm on urinary catheter material. Antimicrob. Agents Chemother., 27(4): 619-24. [PMID:3923925]

Nicolle, L.E. 2005. The catheter related urinary tract infections. Drugs Aging, 22(8): 627-39. [PMID:16060714]

Nitzan, O., Elias, M., Chanzan, B., Saliba, W. 2015. Urinary tract infections in patients with type 2 diabetes mellitus: review of prevalence, diagnosis and management. Diabetes Metab. Syndr. Obes., 26(8): 129-36.

[doi:10.2147/DMSO.S51792.ecollection 2015.]

Pascaul, A. 2002. Pathogenesis of catheterrelated infections: lessons for new designs. Clin. Microbiol. Infect., 8(5): 256-64. [PMID:12047402]

Platt, R., Polk, B.F., Murdock, B., Rosner, B. 1986. Risk factors for nosocomial urinary tract infection. Am. $J$. Epidemiol., $\quad$ 124(6): 977-85. [PMID:3776980]

Priyadarshini, A., Mangaiyarkarsai, T., Balasubramaniam, R., Dhandapany, S.P., Gopal, R. 2014. Biofilm production and antibiotic resistance among uropathogens causing bacteriuria in diabetic individuals. Sch. J. App. Med. Sci., 2(2A): 568-71. [ISSN:2347954X]

Sheretz, R.J. 1997. Pathogenesis of vascular catheter-related infections. In: Seifert H, Jansen B, Farr BM, Dekker MM editors. Catheter-related infections. New York.

Tambyah, P.A. 2004. Catheter-associated urinary tract infections:diagnosis and prophylaxis. Int. J. Antimicrob. Agents, 24S: S44-8. [DOI: http://dx.doi.org/10.1016/j.ijantim icag.2004.02.008]

Traunter, B.W., Darouiche, R.O. 2004. Role of Biofilm in catheter associated urinary tract infections. Am. J. Infect. Control, 32(3):

$177-83$

[Doi:10.1016/j.ajic.2003.08.005]

Warren, J.W., Tenney, J.H., Hoopes, J.M., Muncie, H.L., Anthony, W.C. 1982. A prospective microbiologic study of bacteriuria in patients with chronic indwelling urethral catheters. J. Infect. Dis., 146(6): 719-23. [PMID:6815281]

\section{How to cite this article:}

Pallavi Sayal, Pushpa Devi and Kanwardeep Singh. 2016. Bacterial Colonization and Biofilm Formation among Diabetic Patients: A Therapeutic Challenge. Int.J.Curr.Microbiol.App.Sci. 5(9): 174-181. doi: http://dx.doi.org/10.20546/ijcmas.2016.509.019 